\title{
Understanding and Application of Culturally Diverse Issues Within University Settings
}

\author{
BARRY L. HALL, ${ }^{*}$ JUDITH C. KULIG, ${ }^{\dagger}$ \\ KARRAN THORPE, ${ }^{\dagger} \&$ LUCIA PFEUTI
}

- University of Calgary + University of Lethbridge

\begin{abstract}
This qualitative study focused on exploring the knowledge and beliefs of university faculty, staff and students regarding: the effects of multiculturalism and immigration on their professional lives; the influence of cultural issues within the university setting; and, finally, the teaching and learning needs of culturally diverse students. The major findings include the limited knowledge base held by all groups in the sample about multiculturalism and immigration with subsequent little effect on their professional lives. However, of the three groups, the student group more readily recognized that they have little preparation for the multicultural interactions that will occur in their future professional practices. Although some faculty members included other teaching experiences and strategies to expose students to diversity, they also admitted to a lack of expertise in this area.
\end{abstract}

The authors extend a thank-you to all the participants; Connie Schulz, Research Assistant, as well as secretaries, Wendie Cameron, Wendy Herbers and Patti-Jo Aiken. The authors also acknowledge the financial support for this study provided by the Multiculturalism Programs of the Department of Canadian Heritage and the University of Lethbridge Internal SSHRC Award. 


\section{Résumé}

Cette étude qualitative explore les connaissances et les convictions des professeurs, du personnel universitaire et des étudiants en ce qui a trait aux effets de l'immigration et de la diversité culturelle sur leur vie professionnelle, à l'influence de la question culturelle dans l'environnement universitaire, ainsi qu'aux besoins liés à l'apprentissage et la formation des étudiants de cultures diverses. Les résultats essentiels indiquent la piètre connaissance qu'ont ces différents milieux des questions touchant la diversité culturelle, ce qui a pour corrélat une absence apparente d'influence de cette diversité sur leur vie professionnelle. Toutefois, sur l'ensemble des trois groupes consultés, les étudiants semblent plus prompts à reconnaître leur absence de formation en la matière: ils se sentent peu préparés aux interactions pluriculturelles inhérentes à leur vie professionnelle à venir. Bien que quelques professeurs intègrent à leur enseignement des stratégies et des expériences variées afin d'exposer les étudiants à la diversité culturelle, ils reconnaissent également un manque de compétence spécialisée dans ce domaine.

\section{Introduction}

Canada is becoming increasingly culturally diverse challenging educators in preparing curriculum and learning activities that meet culturally diverse students' needs while educating mainstream Euro-Canadians about the contributions of other cultural groups. Although Canada has an official Multiculturalism Act, there has been little attention given to addressing cultural diversity issues within many institutional settings such as universities.

The present study addressed four general objectives:

1. to explore the knowledge and beliefs of faculty, students and staff about multiculturalism and culturally diverse groups;

2. to identify multicultural issues in the academic setting including the influence of culture and ethnicity on teaching and learning needs;

3. to describe the extent to which culturally diverse issues are met by faculty and staff within education, nursing and social work; and, 
4. to analyze the faculty and staff's perceptions and knowledge of culturally diverse students' teaching and learning needs.

\section{Multiculturalism: Presence and Influence on Educational Settings}

The need to address multicultural issues is supported by demographic trends. In Canada, $31 \%$ of the population reports its background as neither British nor French (Ministry of Industry, 1993). The falling birth rate among the mainstream population in Canada and the United States, along with the rise in immigration from non-European countries, and the higher rate of women of childbearing years among these newcomers all indicate a continuation of a demographic shift (Gay, 1992; Lynch, 1989 cited in Christensen, 1992).

Higher numbers of students from diverse cultural backgrounds are already present in postsecondary institutions (Oliver \& Johnson, 1988). There are estimates that within ten years student populations at institutions such as Stanford and Harvard will be predominantly of Asian extraction (Min, 1995). In Canada, such a situation is likely in cities such as Toronto and Vancouver. Consideration also needs to be given to aboriginal people who comprise over one-half million of the Canadian population (Ministry of Industry, 1993).

As the world has become more globally interconnected, there has been a shift toward a multicultural perspective. In preparation for the workplace of the future, individuals need a greater awareness of cultures (Belay, 1992; Cushner \& Trifonovitch, 1989; Pai, 1984). Multicultural curricula provide students with opportunities to learn about cultures and gain a broader perspective about the world in which they live (Hunt, Bell, Wei, \& Ingle, 1992). In the past, Canadian and American university and college campuses have responded to the increased pressures of higher numbers of multiculturally diverse students by developing separate departments and faculties. For example, programs in Black Studies, Native American Studies and Asian Studies were all created to provide specialized courses (Hunt et al., 1992; Schoem, Frankel, Zuniga, \& Lewis, 1993). This method allowed for students of these backgrounds to learn about their cultural heritage and related issues, yet there was no integration of multiculturalism in college and university setting as a whole (Hunt et al., 1992). Universities have been, in fact, created on cultural assumptions that are European in origin (Anderson, 1988; Hunt et al., 1992) and that have 
silenced multicultural voices (Greene, 1993). Teaching styles, presentation of material that does not incorporate multicultural views, the lack of articles and books that represent alternative views, and the use of traditional evaluative standards for admissions are all examples of how universities further stifle multiculturalism (Shom \& Spooner, 1991).

Professional schools such as education, nursing, and social work need to prepare graduates who can work effectively with the growing multicultural clientele. There are examples that support the need for social workers to be more skilled with multicultural groups (Chau, 1990; D'Andrea \& Daniels, 1991; Dana, 1992; Hirschfield, 1994; Lee, 1991; Merta, Stringham, \& Ponterotto, 1988; Morris, 1993; Nwachuku \& Ivey, 1991; Ronnau, 1994), for teachers who are culturally sensitive to their students needs (Cooper, 1992; Dana \& Lynch-Brown, 1992-1993; Fuller \& Ahler, 1987; Garibaldi, 1992; Larke, 1990; Statistics Canada, 1993), for counsellors who are skilled at multicultural counselling (Dana, 1992; Lee, 1991; Nwachuku \& Ivey, 1991), and for nurses who can assess and incorporate cultural beliefs and values into nursing care (Capers, 1992; Huttlinger \& Keating, 1991; Lenburg et al., 1995; Lynam, 1992; Wuest, 1992).

A number of definitions of multicultural education exists, but in this study it is referred to as an education that uses methodologies and institutional materials which promote equity of information and high standards of academic scholarship in an environment that respects the potential of each student (Swartz, 1992, p. 34). Several approaches to multicultural education exist and include:

1. teaching the culturally different in preparation for assimilation (Sleeter \& Grant, 1987);

2. emphasizing a human relations approach to assist students of different backgrounds;

3. teaching courses on distinct groups to foster cultural pluralism;

4. reforming school programs to include multicultural education and the promotion of social equality and cultural pluralism; and

5. preparing the student to challenge social structural inequality and to promote cultural diversity education that is multicultural and social reconstructionist (Sleeter \& Grant, 1987, p. 422).

Barriers to multicultural education exist and include the way that educators think, prepare and deliver their teaching materials (Schoem et 
al., 1993). Teaching about multiculturalism requires personal and professional risks (Barrett, 1993). The school environment requires complete change when multicultural education is incorporated (Banks, 1993). Belay (1992) argues that multiculturalism is not an addition of new topics but rather a revitalization of education through the infusion of cultural diversity into existing courses that Barret (1993) believes involves personal and professional risks. Identifying approaches and barriers to multicultural education is but one important aspect, just as critical in determining how well prepared are the professors who interact with and teach persons from other cultures. Decades of monocultural instruction have led to a group of educators that is faced with the challenge of teaching large multicultural groups of students. Nonetheless, present day educators need, now more than ever, to incorporate a more pluralistic form of teaching, so that future professionals will be better prepared to work with their multicultural clientele.

\section{Methodology}

A qualitative research methodology was employed in this study, including open-ended interviews, verbatim transcriptions, as well as ongoing data collection and analyses. This specific research includes culture as a principal construct and emphasizes that the researcher and respondent learn together about the subject matter under study.

\section{Sample}

The population comprised faculty, staff and students within the Faculties of Education, Social Work, and Nursing at two universities. In total, at the time of the study, there were 150-160 students and 44 faculty and support staff within the School of Nursing (i.e., the post-RN program only), 200 students and 38 faculty and support staff in the Faculty of Social Work and 350 students and 59 faculty and staff in the Faculty of Education.

In accordance with sampling techniques in qualitative research, for each category of respondents, a range of individuals were to be interviewed until data saturation occurred (Spradley, 1979). A random sample of 50 individuals from the specified disciplines, was interviewed.

Anonymity and confidentiality were addressed in a variety of ways. All respondents received an explanation of the study and were asked to sign a consent form. The respondents were advised about their right to 
refrain from responding to an item, to withdraw from the study at any time, and were also assured that all data collected would be held in confidence. Each respondent was assigned a code that was used for all data entered into computer files. All data - notes, transcripts, and other related materials - were kept in a locked filing cabinet accessible only to the co-investigators and research assistant.

The interviews were carried out by a trained research assistant who was familiar with the needs of culturally diverse populations. All interviews were tape-recorded and transcribed verbatim by the secretary of the research team. Independent of one another, the investigators conducted a content analysis of the transcripts with the purpose of identifying salient categories and themes. This particular method of data analysis reflects the investigators intentions to accommodate trustworthiness and authenticity of the data (Lincoln \& Guba, 1985; Sandelowski, 1986). Throughout the analysis phase, a computer software program (e.g., FolioVIEWS, 1995) was used to organize and analyze the data.

\section{Findings and Discussion}

Demographic information was collected from the respondents at the beginning of each interview, followed by specific questions about their affiliation with organizations that emphasize cultural diversity and their exposure to cross-cultural courses, workshops and the like. The demographics are presented in Table 1, followed by the presentation of the major findings.

\section{Demographics}

All of the respondents interviewed were either studying or working in one of three disciplines, namely education, nursing and social work. The following data have been compiled in relation to the four groups of respondents who were interviewed (i.e., faculty, studentss, advisors and clerical staff).

\section{Faculty}

A total of 16 faculty members was included in the study. The ages of this group ranged from 30 to 55 years, with a mean age of 44.81 years. Of these respondents, $75 \%(n=12)$ were female and $25 \%(n=4)$ were male. See Table 1 for the demographic information (i.e., age, gender and program) by 
Table 1

Demographic Information by Respondent $(n=50)$

\begin{tabular}{lcccc}
\hline & $\begin{array}{c}\text { Faculty } \\
\mathrm{n}=16\end{array}$ & $\begin{array}{c}\text { Student } \\
\mathrm{n}=23\end{array}$ & $\begin{array}{c}\text { Advisor } \\
\mathrm{n}=6\end{array}$ & $\begin{array}{c}\text { Clerical } \\
\mathrm{n}=5\end{array}$ \\
\hline $\begin{array}{l}\text { Gender } \\
\text { Male }\end{array}$ & $4(25 \%)$ & $4(17 \%)$ & 0 & 0 \\
$\quad$ Female & $12(75 \%)$ & $19(83 \%)$ & $6(100 \%)$ & $5(100 \%)$ \\
& & & & \\
Mean Age (years) & 44.81 & 32.87 & 38.17 & 41.20 \\
Range (years) & $30-55$ & $21-52$ & $26-50$ & $29-47$ \\
& & & & \\
Program & & & & \\
$\quad$ Education & 6 & 8 & 2 & 2 \\
$\quad$ Nursing & 5 & 9 & 2 & 2 \\
$\quad$ Social & 5 & 6 & 2 & \\
\hline
\end{tabular}

respondent (i.e., faculty, staff, advisor, and clerical). The responses for ethnic and racial affiliation (that is, cultural variables) are listed in Table 2. It should be noted that the categories for these two questions were not predetermined by the interviewers, but rather the categories were identified by the respondents.

With respect to whether the faculty respondents had ever attended any cross-cultural seminars or workshops, more than half $(56.25 \%, \mathrm{n}=9)$ answered yes. In addition, five $(31.25 \%)$ respondents replied no, and the remaining two $(12.25 \%)$ provided no answer. Some of the courses listed included: Native and cultural awareness, issues in Native education, cultural sensitivity, and cross-cultural issues (general and nursing). At the time of the interview, most respondents $(56.25 \%, \mathrm{n}=9)$ did not belong to any cross-cultural organizations. However, five respondents $(31.25 \%)$ did belong to some cross-cultural organizations. Finally, only four (25\%) faculty members had ever completed a cross-cultural course; the courses listed included Native Education, Gender and Curriculum, and Indian and Northern Education. 


\section{Students}

There was a total of 23 respondents who were students. The ages of these students ranged from 21 to 52 years (see Table 1). Similar to the faculty members, the majority of the students $(82.6 \%, \mathrm{n}=19)$ was female, with only four males $(17.4 \%)$ in this group. There was great variation with respect to ethnic affiliation within this group even though nine students stated having no affiliation (refer to Table 2).

Only five of the students had ever attended any cross-cultural seminars or workshops; however, eight students provided no answer to this question. Some of the examples of types of seminars included: a Native American Professor Presentation, a Native Education Workshop, Native Awareness, Talking Circle, and a Faculty of Education Workshop on Multiculturalism. As well, five students responded that they belonged to some type of cross-cultural organization, for example, the Italian Canadian Club or church support groups for immigrants. More students (43\%) than faculty members $(25 \%)$ had completed a cross-cultural course. The eight students who had completed such courses listed the following types of courses: Native Education and Native American Studies, Cross-cultural Childrearing and Childbearing, Contemporary Canadian Issues, Women's Studies, as well as sociology and anthropology courses.

\section{Advisors}

There were six advisors who provided responses for this study. All of these advisors were female and their ages ranged from 26-50 years. Although this was a relatively small group, the advisors provided a variety of responses with respect to their ethnic and racial affiliation (refer to Table 2).

With respect to whether or not the advisors had ever attended some form of cross-cultural training seminars, only two responded yes. This number was also the same for those advisors who belonged to a cross-cultural organization. One organization listed included Amnesty International. Finally, only one advisor had completed a cross-cultural course.

\section{Clerical Personnel}

The respondents in this group included four secretaries and one clerk typist. The ages of this group ranged from 29-47 years old (see Table 1). The ethnic and racial affiliations of this smallest group have been included in Table 2. As with the advisors, all of the clerical respondents 
Table 2

Cultural Variables of the Sample $(n=50)$

\begin{tabular}{|c|c|c|c|c|}
\hline & $\begin{array}{c}\text { Faculty } \\
n=16\end{array}$ & $\begin{array}{c}\text { Student } \\
\mathrm{n}=23\end{array}$ & $\begin{array}{c}\text { Advisor } \\
n=6\end{array}$ & $\begin{array}{c}\text { Clerical } \\
\mathrm{n}=5\end{array}$ \\
\hline \multicolumn{5}{|l|}{ Ethnic Affiliation } \\
\hline Canadian & 5 & 2 & 2 & 2 \\
\hline French-Canadian & 0 & 0 & 0 & 1 \\
\hline Native American & 0 & 2 & 0 & 0 \\
\hline White Anglo Saxon & 2 & 0 & 0 & 0 \\
\hline British/Scottish/Irish & 2 & 3 & 0 & 0 \\
\hline Continental Europe & 0 & 6 & 2 & 2 \\
\hline Mixed Ethnicity ${ }^{b}$ & 3 & 1 & 1 & 0 \\
\hline None & 4 & 9 & 1 & 0 \\
\hline \multicolumn{5}{|l|}{ Racial Affiliation } \\
\hline Caucasian & 7 & 11 & 4 & 3 \\
\hline Black & 1 & 0 & 0 & 0 \\
\hline Native American & 0 & 2 & 0 & 0 \\
\hline Other ${ }^{c}$ & 2 & 2 & 1 & 2 \\
\hline None & 6 & 8 & 1 & 0 \\
\hline \multicolumn{5}{|l|}{ Country of Birth } \\
\hline Canada & 14 & 22 & 6 & 5 \\
\hline Australia & 1 & 0 & 0 & 0 \\
\hline Holland & 1 & 0 & 0 & 0 \\
\hline England & 0 & 1 & 0 & 0 \\
\hline \multicolumn{5}{|c|}{$\begin{array}{l}\text { Individual respondents self-identified themselves in relation to the above cate- } \\
\text { gories. Hence, the above classification was not predetermined. } \\
\text { bixed Ethnicity - e.g., German/English; African/Canadian; Dutch } \\
\text { Indonesian; Norwegian/German/Scottish } \\
\text { c Other - e.g., Canadian, Indonesian, French-Canadian, Human }\end{array}$} \\
\hline
\end{tabular}


were born in Canada. Finally, all but two clerical respondents have spent their entire lives in this country. Two of the clerical staff had attended some form of cross-cultural training seminars or workshops. These seminars/workshops pertained to cultural diversity and increasing support staffs understanding of different cultures. Only one member within this group belonged to a cross-cultural organization, (i.e., Immigrant Aid Society). In regard to ever having completed a cross-cultural course, only one respondent answered yes.

\section{Interview Findings}

From the independent and collaborative analyses, the following three categories emerged:

1. There is a level of knowledge and integration by faculty and staff (clerical personnel and advisors) regarding multiculturalism and immigration with effects on their professional lives.

2. There is a level of knowledge and integration by students regarding multiculturalism and immigration with the effects on their professional lives.

3. The degree to which principles and tenets of multiculturalism are espoused in a university learning environment varies.

The following discussion provides detailed information about each of the categories; comparisons between the findings and the literature are also made.

\section{Faculty and Staff's Knowledge and Integration of Multiculturalism}

The faculty and staff's knowledge regarding multiculturalism and immigration can be set within a broader context of how they perceive their own identity. Such a discussion is important because it provides clues regarding the faculty members perceptions of concepts such as culture, diversity, assimilation and integration. It was found that most faculty and staff indicated some ethnic or racial affiliation (see Table 2). During the interviews the respondents were asked if they considered themselves culturally diverse. Interestingly, a number of them did not understand this question but interpreted it to mean whether or not they were open to other cultures rather than being asked about their adherence to a particular culture. In several of the interviews, the interviewer had to explain the question further or ask if they considered their culture to be Canadian. 
The discussions with the respondents about their understanding of multiculturalism and its influence on their professional life proved to be very fruitful. By far, the most frequently noted definition of multiculturalism among the respondents was that it represented different cultures coming together and attempting to work together in a sense of unity. Some respondents understood the complexity of the term and discussed it on different levels. Although this definition sounds very positive, there were some strong sentiments held about the rifts between groups and some allegations of unrealistic expectations of culturally diverse groups in Canada.

One of the clerical respondents related how Canada used to be referred to as a melting pot and that has since resulted in a country that is very diverse with people and practices from various parts of the world. Another clerical respondent made a comment that multiculturalism was not a serious endeavor. The advisors, like the other respondents, saw multiculturalism as something that brought people together; in the words of one of the advisors, it was noted as something that promotes tolerance of other cultures. A clerical respondent noted, "And the multiculturalism, I feel, should be paid for by the culture - because if they want to preserve their culture, thats up to them."

A few faculty members felt that multiculturalism was an abstract concept with little practical purpose. For example, one faculty member noted how it was not helpful in the teaching arena. However, another faculty member noted how multiculturalism was a social policy that gave credence to cultural practices of multicultural groups, a resource for different ethnic groups, and a political tool for politicians to potentially secure votes from more individuals. In contrast to some of the opinions of other faculty members, one individual naturally associated multiculturalism with cost and the use of taxes to support certain initiatives.

In summary, the faculty and staff do have some knowledge of multiculturalism. However, in comparison to the literature, the definition of multiculturalism that was forwarded by the faculty and staff is very narrow. Although a number of definitions exist, Fleras and Elliott (1992) have adopted the following one:

... multiculturalism is an official doctrine and corresponding set of policies and practices in which ethnoracial differences are formally promoted and incorporated as an integral component of the political, social, and symbolic order (p. 22). 
This definition indicates that multiculturalism is a philosophy, a process by which ethnoracial groups secure a different relationship with central authorities, and an expression of diversity as an intrinsic value. Multiculturalism is also experienced at individual, group, institutional and societal levels. Only one faculty member saw the complexity of multiculturalism and defined it at various levels. The inability of the other respondents to view multiculturalism more broadly may be related to a number of factors including the recent passage of the Multiculturalism Act in 1988 (Fleras \& Elliott, 1992).

The respondents were also asked how multiculturalism affected their professional lives with several of them responding that it did not affect them in any way. One noted how she had become more cynical because some culturally diverse groups comment about the advantages of their country over Canada. This individual felt that these people should return to their home land rather than remain here. What this individual did not recognize, however, is that such comments can either represent phases of culture shock that all individuals from different countries experience, even after several years of being in their new homeland, or else a sense of nostalgia for their homeland that cannot be realized. Furthermore, the comment by the clerical respondent is an example of the negativity about multiculturalism that has been noted in Canada (Fleras \& Elliott, 1992).

Faculty members provided divergent opinions about how multiculturalism affected their professional lives. One faculty member noted that the conferences on multiculturalism were artificial with little gain for the educator. It was acknowledged that operationalizing multiculturalism in university departments is difficult. In one faculty members department there was discussion about the need to include multicultural content but there was no direction about how this was to be accomplished. One other faculty member who maintains a clinical practice noticed the extra time needed to make a connection with clients while trying to understand their culture and the influence it has on their lives. It is interesting to note that one faculty member felt inadequate, stating that," "I can't possibly know everybody's world view," while another faculty member acknowledged that it broadened the definitions of what teaching and learning were all about because of looking at other cultures and their world views.

The lack of awareness of the need for addressing cultural issues points to the failure to operationalize multiculturalism and to incorporate it within the basic mission of the university (Bowser et al., 1993; Mazon 
\& Ross, 1990; Shom \& Spooner, 1991). It also shows the need for using cross-cultural training models with faculty members to raise their awareness and prepare them to begin to address the cultural issues encountered by their students. A number of models exist that emphasize the necessity of addressing beliefs and attitudes, knowledge and skills of the respondents (Leong \& Kim, 1991). In addition, there are a number of teaching strategies suggested in the literature (e.g., Capers, 1992; D'Andrea \& Daniels, 1991; Gunter, 1988; Wuest, 1992) to prepare students for their multicultural clientele that could be accessed by faculty members. Despite the obvious growing multicultural clientele, there is little concentrated effort to meet the needs of future graduates who will interact with these groups. Multiculturalism is seen as an abstract concept that is not grounded in the preparation or delivery of material to future graduates in the fields of education, nursing and social work. Those few faculty members who are attempting to deal with the varying world views of students or clients are largely alone in their efforts.

\section{Students' Knowledge and Integration of Multiculturalism}

Like the other respondents, the students were asked to identify their cultural background on the demographic information sheet. The students were also asked if they considered themselves culturally diverse; some of the respondents had difficulties in understanding this question. One of the students indicated that in their family they still have certain foods that are culturally based but consider themselves to be Canadian. One of the aboriginal students indicated that she was brought up to live in two worlds but that she was primarily a Blackfoot person. In contrast, another aboriginal student did not consider herself strongly culturally based but upheld aboriginal spirituality.

Of all the groups, the students had the most difficulties in articulating what is multiculturalism. Some had taken classes on the subject or had done classroom presentations and, thus, were able to provide a definition that was similar to comments provided by the faculty members, advisors and clerical personnel. By and large, the student population is young and has not experienced the same social and historical context within Canada as the other respondents who were adults when the Multiculturalism Act was passed in 1988. One of the students believed that multiculturalism was an ideal that was worth working toward. For one student, multiculturalism meant the richness of any situation because 
of their differences that are culturally based. In contrast, one student felt that culture was just an added-on characteristic that did not make people necessarily unique. Another opinion was that a monoculture could not be successfully imposed on groups. Finally, one student recognized that some cultures remained distinct from Canadian culture, which was seen as an integration of different cultures together.

The students had interesting comments to make regarding the effect of multiculturalism on their professional lives. Several noted nervousness about working in their practice profession because they did not perceive themselves as having the skills to work with culturally diverse clients. In general, the students talked about the need to be open to other people's viewpoints and to consider diversity in the planning of care, either as a social worker or as a nurse, or the development of teaching strategies as teachers. One student said, "It just gives me . . . a variety of different ways of approaching different counseling situations." One education student felt that teachers were being asked to move beyond the boundaries of being a teacher and at times to take on the role of a social worker. The nursing students recognized the impact of multiculturalism on their practice because of the different cultural beliefs and practices that needed to be considered and accommodated in some way. These students gave specific examples of incidents with clients where they were unsure if the appropriate solution had been generated.

It is intriguing that the students recognized more readily their need to acquire cross-cultural skills compared to some of their professors. It can be speculated that the professors without a clinical or teaching component to their position are either not aware, or are unwilling to be aware, of the changes in society regarding the influx of culturally diverse groups and the impact this has for their future graduates. The literature (e.g., Chau, 1990; Cooper, 1992; Huttlinger \& Keating, 1991) confirms that students in the fields of education, nursing and social work need to be prepared to work with the multicultural clientele that comprise society.

\section{The University as an Open Learning-Environment}

Information was also collected about the student respondents perceptions of issues such as the presence of a competitive environment within the university and reverse discrimination in the classroom. As part of the study, the investigators queried if the current highly competitive nature of university education for students would have a bearing on learning opportunities in 
diversity and multiculturalism. The investigators employed a microapproach by analyzing whether or not students would concern themselves with the rich learning opportunities of being with diverse students in the classroom. In other words, is competitiveness and the continual struggle for high marks a barrier to learning about diversity?

The results indicated that students are very eager to explore the resources available to them within their own classroom, that is, students from other cultures. One respondent said, "professors have to realize that they have other cultural people in their classrooms. We are going to meet up with different people from different cultures. Students need to seek out and learn from those other cultural people." Once again, the repeated theme was that students felt very strongly that they were not receiving the required and necessary information about diversity within their professional training. One student stated, "I don't think we learned a whole lot from the professors," while another commented that, "very little is happening in our classrooms that takes into consideration peoples from other cultures." As with other sections in this report, the student concerns reflect the findings of authors of previous research studies (Bergen, cited in Dana, 1991; Capers, 1992; Cooper, 1992; Martin, 1991). Despite such calls for change, little movement, as evidenced by this study, has been achieved to providing quality multicultural education. Part of the problem lies within faculty who do not have the knowledge and feel inadequate in teaching diversity in the professional faculties. This lack of multicultural preparation of faculty members further confirms Bernhard et al. (1995) and Toumishey's (1989) findings. The other part is the lack of serious institutional change that supports and provides resources for professors to be better able to teach multicultural education. The results of this research show that students are wanting knowledge about diversity and will utilize all resources available, particularly those opportunities in the classroom. A number of respondents spoke very positively about the benefits of having students from other cultures as part of the class. Interestingly, the majority of examples given by the students focused on aboriginal persons. One student suggested that "if the native student hadn't been there (in the classroom) I don't think we would have learned anything about Aboriginal people."

The cooperative learning model certainly would go a long way to address this problem in that students would be able to interact within a small group setting. One respondent found it personally very exciting to be able to interact with a person from another culture, 
"I found it a really great experience to actually meet and understand the Native culture a little bit better - with her being in it. That was probably the biggest distinction in the class and it seemed everyone really respected her and wanted to learn from her, it was really neat."

Overall, students seemed to express a strong desire to learn knowledge about other cultures from the actual people in that culture.

The question to be asked is whether or not that which is espoused as academic freedom is actually operationalized within the classroom. If part of the learning process is to allow freedom of expression of different view points then the manner in which information is delivered can clearly act as a catalyst for both the quality and quantity of student discussion. Results from the faculty interviews stated that the professors certainly were in favor of cooperative learning, that is breaking into small groups, which supports previous work on teaching strategies (Sawyer, 1991; Swicher \& Deyhle, 1989). As one professor stated, "cooperative learning is an experience ... the student is more in control and the professor needs to be more collaborative." However, the study results showed that there was far more traditional didactic lecturing going on as opposed to the more interactional model. This is not to say that cooperative learning does not occur in the classroom, but within the class time the amount of student processing information among themselves tends to be quite limited.

This study identified barriers to the cooperative learning model and its application to multicultural classroom teaching. In particular, some professors pointed out that due to the cutbacks within the universities, class sizes are increasing quite dramatically and this, as a system problem, prevents the utilization of an effective cooperative model of teaching. Yet, on the other hand, for those professors who attempted to use a cooperative model, some felt that it allowed the different cultures to stay in their own separate learning groups and much effort was required to mix the student groups in regard to diversity.

The response from the students was such that they were very clear in discussing how they viewed professors having clear biases, despite a number of faculty having reported on the importance of being aware of their own biases, and not allowing these to colour the delivery of opposing views while in class. The student responses echo the concerns of many researchers as far back as the works of Abu-Saad, Kaysar-Jones 
and Gutierrez (1981), and recently Crow (1993). It appears that little has changed beyond the understanding of the need to be aware of the impact of differing values and belief systems within a university classroom. Concerns raised by the students included: professors' biases and world views affecting their own backgrounds, which can be damaging to the students; professors do not have an adequate knowledge base to teach multiculturalism; students cannot learn about a culture in a limited amount of time; a guest speaker talking about diversity is simply not sufficient; and, none of the course textbooks addressed issues related to cultural diversity.

Within the interviews, the respondents were also engaged in discussion about how classroom dynamics were influenced by the culturally diverse student body. Specifically, incidents were examined for evidence of being discriminatory toward the majority, that is, Caucasians, or toward members of a culturally diverse group. As well, the interviews were examined for incidents of perceived special treatment of certain groups and the interpretation of that treatment by the individual who was being interviewed. Interestingly, most of the examples deal specifically with aboriginal students.

Clerical personnel provided examples of special treatment toward certain students. For example, one individual said, "I notice one of the professors had a native student who just couldnt get the assignments in - you know, that kind of thing is a bit of a problem, because they don't recognize time lines or deadlines." This individual gave a further example in relation to an international student: ". . . she didn't realize that a hand had been extended to help her and she wasn't responding and that frustrated the (professor)." For this individual, aboriginals in particular were given special treatment while they were completing their requirements at the university. In these examples, the respondents lacked the knowledge and understanding of the complexity of individuals' lives and the inter-relationship of social and cultural issues. Furthermore, the behaviour of the aboriginal student was stereotyped when reference was made to the individual student not recognizing timelines. In contrast, one other clerical respondent noted that culturally diverse students have special needs because they are out of their culture. One advisor noted that there was no discrimination between the students within the program with which the person is associated.

Within the faculty, there were few comments about special treatment or reverse discrimination. However, one comment was that people who 
do not fit into the mainstream paradigm are automatically labeled as needy, leading to the development and implementation of programs such as those for children with special needs. Overall, this faculty member felt that a move to a more holistic form of assessment and program development was more appropriate.

The students had considerably more to say on the topic of reverse discrimination. One aboriginal student emphasized that the patronizing attitude toward aboriginal society as being "defective" needed to be abandoned. Students also gave examples of members of certain cultural groups sitting together, which had caused problems in some classes. However, one student interpreted this as normal behavior; "I do that, too, with people of my own age." Some of the students indicated that students, regardless of cultural background, intermingled within the classroom and that in the practice arena, they were not aware of any blatant discriminatory practices against culturally diverse clients.

In terms of the actual classroom teaching, there were several incidents that are noteworthy. One student mentioned how a classroom presentation by aboriginal individuals became "white bashing" and was not helpful in understanding the current situation of aboriginal people. Being culturally diverse becomes evident for those groups when specific information about the group to which they belong is presented in class; one student (who was not culturally diverse) expressed this point in the comment, "that would just reaffirm that I am definitely a minority or I'm definitely different because they are studying different cultures and they are talking about me."

There were descriptions of incidents in which the student felt that the professor was discriminatory to the non-aboriginal students in the class. As one student remarked:

Actually, this professor approached me, being an older student, and wanted to know why he wasn't reaching some of the students. I had to tell him that I thought he was running a reverse discrimination sort of policy. . . What came out of that was a well-meaning attempt to make people feel more comfortable.

One last example is that of a professor who made a prejudicial comment in class, which was offensive to the student who related the incident and to a fellow student who was a member of that group. In further defense of incidents such as this, one student said, "There are some professors who are very racist." An interesting twist to reverse discrimination was 
offered by one professor who provided an example of one student who appeared to know the educational system well, how it worked, and how to use the system to his advantage. In this situation, the professor felt disadvantaged because the student deliberately used cultural diversity to enhance his position in the classroom.

The classroom setting does not mirror the image presented by the respondents that multiculturalism represents culturally diverse individuals working together. The students provided poignant examples of professors who were unable to exclude their personal beliefs and stereotypes from the classroom. Although there were some incidents where negative feelings were experienced between groups, for the most part, the students accept culturally diverse students despite some concern of differential treatment in admissions, hiring and assignment of grades based upon cultural background.

\section{Recommendations}

There are a number of recommendations based upon the findings of this study. All of the following suggestions are equally important to begin the process of incorporating multiculturalism within university settings.

\section{Institutional Change}

1. Senior administrators within universities need to demonstrate leadership and a commitment to supporting multiculturalism through their actions (e.g., provision of educational activities for all faculty and staff members) and resources (e.g., people, time, and money).

2. Administrators need to give serious consideration to hiring practices so that all diverse groups are represented in all levels of the organization.

3. University administrators need to begin the process of diversifying their institutions by undergoing a review and change in their policies and procedures and incorporating workshops as necessary for faculty and staff and encouraging departments and faculties to revise their curriculum accordingly. 
4. Senior university administrators need to provide increasing opportunities for persons from other cultures to have access to a university education.

\section{Curricula Issues}

1. All university students need to complete a course that focuses on multiculturalism and cultural diversity issues. This course, however, should also include information about the immigration process to dispel the myths that individuals hold about the arrival of immigrants to Canada. Other universities have begun such an initiative in an attempt to prepare future graduates for the changing world within which they live.

2. The curriculum of professional schools, such as education, nursing, and social work, needs to incorporate concepts of multiculturalism in order to ensure that this knowledge is operationalized at the practice level.

3. Students need to provide input into the essence of these courses so that the topics and foci of the discussions meet their needs and reflect the multitude of cultural groups in our society.

\section{Teaching and Learning Issues}

1. Professors need to appropriately utilize the experiences of diverse students in the classroom.

2. There needs to be more emphasis of the cooperative learning model that will utilize the diversity of the student population.

3. Promotion of cooperative learning in the classroom needs to occur. Professors may need to attend workshops to learn new teaching strategies beyond the traditional lecture format.

4. There needs to be integration of multicultural learning opportunities for students on a planned and regular basis throughout the academic terms.

5. Faculty members need to ensure that students are able to demonstrate at least a beginning level of competency in 
working with individuals from various cultural groups (e.g., demonstrated through assignments and practicums).

\section{Cultural Awareness}

1. University professors need to be prepared in multicultural issues in order to assist in preparing graduates for the future. This may be attained by incorporating cross-cultural workshops for current faculty and including multicultural content in all university degree programs, with a special emphasis in professional schools such as education, nursing and social work.

2. Professors need to be constantly alert on how their biases and belief systems influence the way to teach within a multicultural framework.

\section{Conclusion}

While many respondents supported the value of multiculturalism, their perceptions of this concept were somewhat narrow in scope and even inaccurate at times. Multiculturalism is indeed a complex concept, one that needs to be embraced at all levels of institutions if the essence of its nature is to be realized. Despite a governmental initiative, as evidenced by the passing of the 1988 Multiculturalism Act, there appears to be an inconsistent approach to implementing appropriate actions at the institutional level. According to the findings of this study, considerable work remains to be done within university settings in order to achieve quality multicultural education for future practitioners in education, nursing, and social work. Since the cultural diversity of the Canadian population is steadily increasing, it behooves all citizens to acknowledge the important contributions that differences among us make to the enrichment of the nation as a whole. There will be no significant change in society until university education personnel at all levels demonstrate leadership in promoting and modeling true multiculturalism. 


\section{References}

Abu-Saad, H., Kaysar-Jones, J., \& Gutierrez, Y. (1981). Latin American nursing students in the United States. Journal of Nursing Education, 21(7), 16-21.

Banks, J. (1993). The canon debate, knowledge construction, and multicultural education. Educational Researcher, 22(5), 4-14.

Barrett, M. (1993). Preparation for cultural diversity. Experiential strategies for educators. Equity \& Excellence in Education, 26(1), 19-26.

Belay, G. (1992). Conceptual strategies for operationalizing multicultural curricula. Journal of Education for Library \& Information Science, 33(4), 295-306.

Bernhard, J.K., Lefebvre, M.L., Chud, G., \& Lange, R. (1995). Paths to equity: Cultural, linguistic and racial diversity in Canadian early childhood education. North York, ON: York Lanes.

Bowser, B., Auletta, G., \& Jones, T. (1993). Confronting diversity issues on campus. Newbury Park: Sage.

Capers, C.F. (1992). Teaching cultural content: A nursing education imperative. Holistic Nursing Practice, 6(3), 19-28.

Chau, K.L. (1990). A model for teaching cross-cultural practice in social work. Journal of Social Work Education, 26(2), 124-133.

Christensen, C. (1989). Cross-cultural awareness development: A conceptual model. Counselor Education \& Supervision, 28, 270-287.

Cooper, A. (1992). Bearing witness: A seminar on cultural diversity for teachers. (ERIC Document Reproduction Service No. ED 350 274).

Crow, K. (1993). Multiculturalism and pluralistic thought in nursing education: Native American world view and the nursing academic world view. Journal of Nursing Education, 32(5), 198-204.

Cushner, K., \& Trifonovitch, G. (1989). Understanding, misunderstanding: Barriers to dealing with diversity. Social Education, 53(5), 318-322.

D'Andrea, M., \& Daniels, J. (1991). Exploring the different levels of multicultural counseling training in counselor education. Journal of Counseling and Development, 70(1), 78-85.

Dana, N.F., \& Lynch-Brown, C. (1992-1993). Children's literature: Preparing preservice teachers for the multicultural classroom. Action in Teacher Education, 14(4), 45-51.

Fleras, A., \& Elliott, J.L. (1992). Multiculturalism in Canada: The challenge of diversity. Scarborough, ON: Nelson.

FolioVIEWS infobase production kit Version 3.1 (1995). Provo, UT: Folio Corporation.

Fuller, M.L., \& Ahler, J. (1987). Multicultural education and the monocultural student: A case study. Action in Teacher Education, 9(3), 33-40.

Garibaldi, A. M. (1992). Preparing teachers for culturally diverse classrooms. In M.E. Dilworth (Ed.), Diversity in Teacher Education (pp. 23-39). San Francisco, CA: Jossey-Bass. 
Gay, G. (1992). The state of multicultural education in the United States. In $\mathrm{K}$. Moodley (Ed.), Beyond multicultural education: International perspectives (pp. 41-65). Calgary, AB: Detselig Enterprises, Ltd.

Greene, M. (1993). The passions of pluralism: Multiculturalism and the expanding community. Education Researcher, 22(1), 13-18.

Gunter, L. (1988). Notes on a method for teaching transcultural nursing. Recent Advances in Nursing, 20, 122-136.

Hirschfield, C. (1994). Using classroom quality circles to combat Japanophobia. The Social Studies, 85(1), 11-15.

Hunt, J., Bell, L.A., Wei, W., \& Ingle, G. (1992). Monoculturalism to multiculturalism: Lessons from three public universities. In M. Adams (Ed.), Promoting diversity in college classrooms: Innovative responses for the curriculum, faculty, and institutions (pp. 101-114). San Francisco, CA: Jossey-Bass.

Huttlinger, K., \& Keating, S.B. (1991). Understanding cultural diversity through a student exchange program. Nurse Educator, 16(5), 29-33.

Larke, P. J., Wiseman, D., \& Bradley, C. (1990). The minority mentorship project: Changing attitudes of preservice teachers for diverse classrooms. Action in Teacher Education, 12(3), 5-11.

Lee, C. (1991). Multicultural counseling perspectives for the 1990s and beyond. Counseling \& Human Development, 23(5), 1-8.

Lenburg, C., Lipson, J., Demi, A., Blaney, D., Stern, P., Schultz, P., \& Gage, L. (1995). Promoting cultural competence in and through nursing education: A critical review and comprehensive plan for action. Washington, DC: American Academy of Nursing.

Leong, F.T.L., \& Kim, H.H.W. (1991). Going beyond cultural sensitivity on the road to multiculturalism: Using the Intercultural Sensitizer as a counselor training tool. Journal of Counseling and Development, 70(1), 112-118.

Lincoln, Y.S., \& Guba, E. G. (1985). Naturalistic inquiry. Beverly Hills, CA: Sage.

Lynam, M.J. (1992). Towards the goal of providing culturally sensitive care: Principles upon which to build nursing curricula. Journal of Advanced Nursing, 17, 149-157.

Martin, R.J. (1991). The power to empower: Multicultural education for student-teachers. In C.E. Sleeter (Ed.), Empowerment through multicultural education (pp. 287-297). Albany, NY: State University.

Mazon, M., \& Ross, H. (1990). Minorities in the higher education pipeline: A critical view. The Western Journal of Black Studies, 14(3), 159-165.

Merta, R.J., Stringham, E.M., \& Ponterotto, J.G. (1988). Simulating culture shock in counselor trainees: An experiential exercise for cross-cultural training. Journal of Counseling and Development, 66, 242-245.

Min, P.G. (1995). Future prospects of Asian Americans. In P.G. Min (Ed.), Asian Americans: Contemporary trends and issues (pp. 271-281). Thousand Oaks, CA: Sage. 
Ministry of Industry, S.T. (1993). Ethnic origin - The nation. Ottawa, ON: Statistics Canada.

Morris, J.K. (1993). Interacting oppressions: Teaching social work content on women of color. Journal of Social Work Education, 29(1), 99-110.

Nwachuku, U., \& Ivey, A. (1991). Culture-specific counselling: An alternative training model. Journal of Counselling \& Development, 70(1), 106-111.

Oliver, M., \& Johnson, J. (1988). The challenge of diversity in higher education. The Urban Review, 20(3), 139-145.

Ronnau, J.P. (1994). Teaching cultural competence: Practical ideas for social work educators. Journal of Multicultural Social Work, 3(1), 29-42.

Sandelowski, M. (1986). The problem of rigor in qualitative research. Advances in Nursing Science, 8(3), 27-37.

Sawyer, D. (1991). Native learning styles: Shorthand for instructional adaptations? Canadian Journal of Native Education, 18(1), 99-105.

Schoem, D., Frankel, L., Zuniga, X., \& Lewis, E. (1993). The meaning of multicultural teaching: An introduction. In D. Schoem, L. Frankel, $\mathrm{X}$. Zuniga, \& E. Lewis (Eds.), Multicultural teaching in the university (pp. 1-12). Westport, CT: Praeger.

Shom, C., \& Spooner, S. (1991). Minorities and the egalitarian-meritocratic values conflict in American higher education: New answers for an old problem. Journal of Multicultural Counseling \& Development, 19(4), 182-190.

Sleeter, C., \& Grant, C. (1987). An analysis of multicultural education in the United Stated. Harvard Education Review, 57(4), 421-441.

Spradley, J. (1979). The ethnographic interview. Toronto, ON: Holt, Rinehart, \& Wilson.

Statistics Canada (1993). Schooling, work and related activities, income, expenses and mobility: 1991 Aboriginal Peoples Survey. Ottawa, ON: Author.

Swartz, E. (1992). Multicultural education: From a compensatory to a scholarly foundation. In C. Grant (Ed.), Research and multicultural education: From the margins to the mainstream (pp. 32-43). London: Falcner Press.

Swicher, K., \& Deyhle, D. (1989). The styles of learning are different, but the teaching is just the same: Suggestions for teachers of American Indian youth. Journal of American Indian Education (Special Issue), 1-14.

Toumishey, H. (1989). Strangers among strangers: Clients and health practitioners in health care settings. Nurse Education Today, 9, 363-367.

Wuest, J. (1992). Joining together: Students and faculty learn about transcultural nursing. Journal of Nursing Education, 31(2), 90-92. 